Online in the US, Personal Identity is Increasingly Political

\author{
Jason Jeffrey Jones * \\ https://orcid.org/0000-0002-4140-0268
}

Department of Sociology and Institute for Advanced Computational Science, Stony Brook University

Nick Rogers

https://orcid.org/0000-0003-0624-8413

Department of Sociology, Stony Brook University

\begin{abstract}
Author Note
* Corresponding author: Jason Jeffrey Jones, jason.j.jones@stonybrook.edu
\end{abstract}

This material is based upon work supported by the National Science Foundation under Grant No. (IIS-

1927227). 


\begin{abstract}
We estimate the prevalence of including political affiliation in one's public profile among American users of Twitter. In 2020, we estimate that more than 1 in 100 users do so, and that this proportion has consistently increased every year from 2015. By our definition and within our sample, the prevalence of political affiliation surpassed religious affiliation in 2018. Informal expressions of political ideology (e.g. the acronyms BLM and MAGA) followed the same trajectory. We encourage further study of the temporal dynamics of identity through exploration of public profile biography data.
\end{abstract}




\section{Online in the US, Personal Identity is Increasingly Political}

In the United States, affective political polarization - an interpersonal distaste between people of competing ideological views - has reached alarming levels. We suspect that this is partly due to an intertwining of political ideology and personal identity. Social Identity Theory (Tajfel \& Turner, 1979) and Realistic Group Conflict Theory (Sherif, 1961) suggest that when individuals see themselves as belonging to a group in conflict with another, the individuals' behavior tends to warp in predictable ways. In a phenomenon termed group polarization, the opinions of each group member become more extreme and certain (Sunstein, 2002). Contrary opinions from outside the group are perceived as threats against the members' sense of identity. Otherwise routine debate, then, becomes unduly personal.

Here we aim simply to measure to what degree political ideology is enmeshed within Americans' personal identity and observe this quantity over time. We do so with a sample of about 10 million American users of Twitter each year 2015 through 2020.

\section{Visualization}

\section{Prevalence of Users whose Bio Contains Category Identifier}

Cross-sectional sample of American users of Twitter in each year 2015-2020

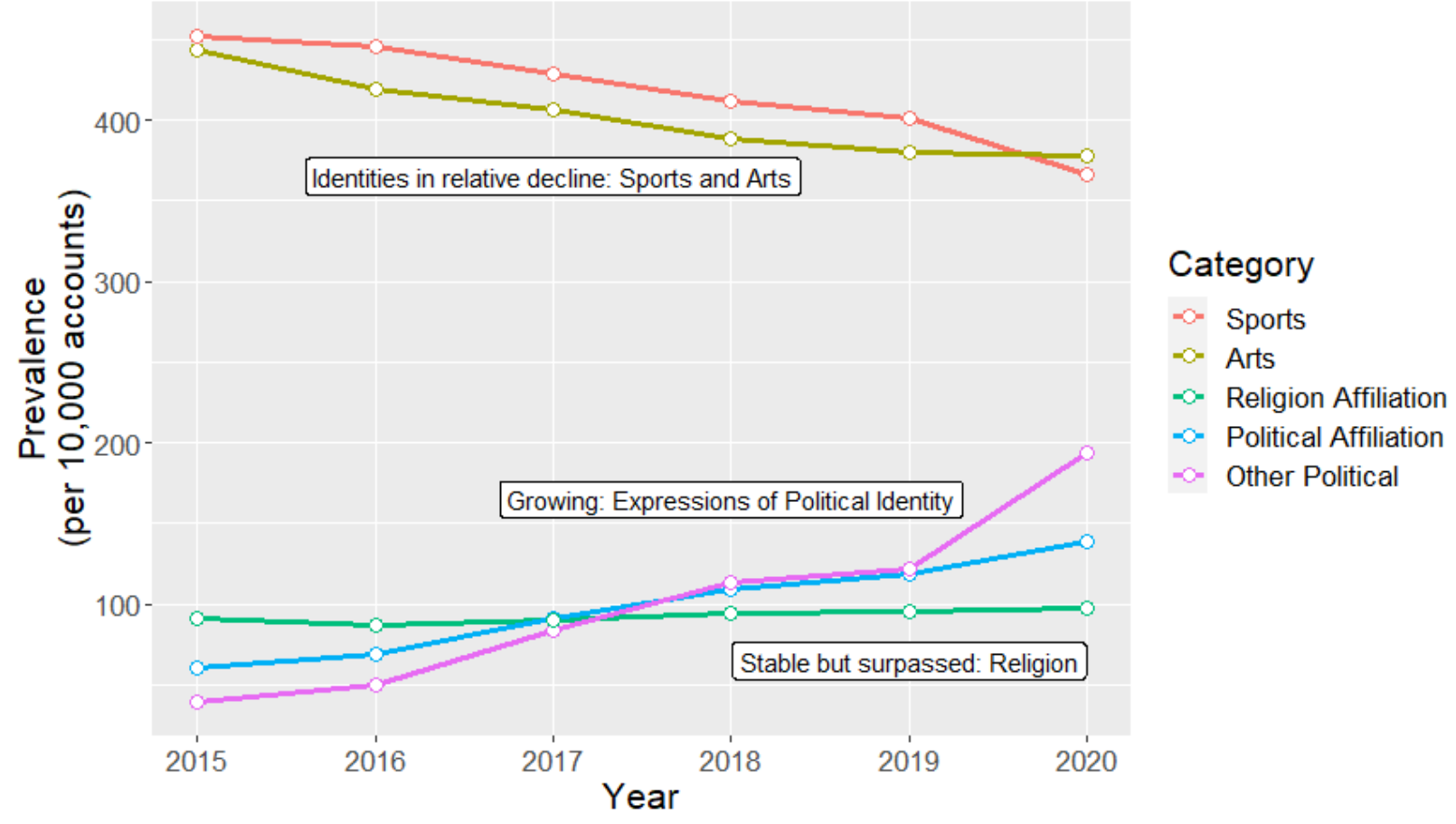




\section{Findings and Discussion}

As our figure visualizes, the prevalence of users including politics in their identity is on a steady rise. Beginning in 2018, US Twitter users were more likely to define themselves with a political affiliation than a religious affiliation. Although other types of descriptors - e.g. those referring to sports or arts - are more common, those types are declining in prevalence. These data suggest that politics is becoming a more salient (see Stryker \& Serpe, 1994) aspect of individual Americans' identities. To the extent that it is, we should expect that the dynamics of group polarization and Realistic Group Conflict Theory have activated accordingly. By that process, Americans sorted into one or another political "team" would find their ideologies becoming more coherent, extreme, and immovable. Expressions of contrary political opinions become felt as personal affronts, leading to a feedback loop of intergroup animus. Prior research has suggested that such toxic cycles may be escaped if a unifying identity (e.g. "American") supersedes the sectarian identity in salience (Lavendusky, 2018), or if an obvious "superordinate" challenge requires intergroup cooperation to achieve (Sherif, 1961). But it is difficult to predict whether this will occur. Our data show the trend of political content increasing in prevalence within personally expressed identity has continued over six years.

\section{References}

Lavendusky, Matthew S. 2018. “Americans, Not Partisans: Can Priming American National Identity Reduce Affective Polarization?” Journal of Politics 80(1):59-70.

Sherif, Muzafer et al. 1961. Intergroup Conflict and Cooperation: The Robbers Cave Experiment. Norman, OK: University Book Exchange.

Stryker, Seldon, and Richard Serpe. 1994. "Identity Salience and Psychological Centrality : Equivalent , Overlapping , or Complementary Concepts?" Social Psychology Quarterly 57(1):16-35.

Sunstein, Cass R. 2002. “The Laws of Group Polarization.” Journal of Political Philosophy 10(2):17595.

Tajfel, Henri, and John Turner. 1979. "An Integrative Theory of Intergroup Conflict.” in The Social Psychology of Intergroup Relations, edited by W. G. Austin and S. Worchel. Monterey, CA: BrooksCole. 


\section{Supplemental Material for}

\section{Online in the US, Personal Identity is Increasingly Political}

\section{Background}

One aspect of the broader phenomenon of political polarization is affective polarization - personal dislike and antagonism between partisans. Affective polarization has been on a steady rise in the United States. (Abramowitz and Webster, 2016; Iyengar and Westwood, 2015; Pew Research Center, 2016). Writ large, the resulting toxicity can gridlock government (Jones, 2001), lead to cultural schisms (Hetherington and Weiler, 2018; Mason, 2018), and even devolve to violent tribalism (Chua, 2018).

But what is the root cause of affective polarization? We think it is partly due to an individuals' incorporation of political affiliation into their sense of personal identity. When an individual forms an identity around a particular group membership, the individual tends to change in predictable, measurable ways. For example, their values and beliefs become more extreme and intractable. (Sunstein, 2002). And they develop a volatile defensive posture against perceived threats to the group, especially rival outgroups. (Sherif, 1958, 1961). We suppose that the salience of politics within personal identity has risen in tandem with growing affective polarization. The intent of the current work is to provide a consistent and persistent measure of the salience of political identity.

\section{Method}

Personal identity is difficult to operationalize and measure. Identity cannot be directly observed. However, language is deeply expressive, and a straightforward approach to operationalizing identity is to ask individuals to describe themselves with words.

Accordingly, for many years identity has been examined through the "Twenty Statements Test" ("TST"), in which respondents were asked to list a number of words that describe them, and the substance of those words could then be analyzed for insights. (Kuhn and McPartland, 1954). When administered broadly and across time, the TST can measure society-wide trends in identity. For example, Zurcher (1977) argued that Americans had become increasingly likely to list personal traits (e.g. "smart"; "hard- 
working") and less likely to list group affiliations (e.g. "Freemason"; "New Yorker"). This was inferred to reflect a widespread cultural shift away from collectivism and toward individualism.

We argue that a modern digital analog to the TST is the social media "bio" where users are prompted to briefly describe themselves (Jones, 2021; Rogers \& Jones, 2021). On Twitter, specifically, the user is asked to "Describe yourself in 160 characters or less" as they create their account. The response is the user's bio, and it appears beneath their picture and name. Users can edit their bio at any time.

This publicly available, self-authored, self-description may contain anything the user chooses. Some people leave the field blank. Some include a quotation. Many simply list words that describe themselves. Recent work has demonstrated that social identities are frequently present within selfdescriptions (Pathak, Madani \& Joseph, 2021). Users update these markers in response to events - the January 6, 2021 attempted insurrection, for example (Eady, Hjorth, Dinesen, 2021). In this work, we tally the prevalence of users whose bio contains a word from categories we constructed to reflect different aspects of identity.

We were specifically interested in measuring the category of Political Affiliation. To construct this category, we listed words we thought explicitly signaled political affiliation. For comparison, we constructed lists for Sports, Arts, Religion Affiliation and Other Political words. Lists of keywords for each category are contained in Table S1.

\begin{tabular}{|l|l|l|l|l|}
\hline Sports & Arts & $\begin{array}{l}\text { Religion } \\
\text { Affiliation }\end{array}$ & $\begin{array}{l}\text { Political } \\
\text { Affiliation }\end{array}$ & Other Political \\
\hline athlete & art & atheist & anarchist & activist \\
\hline baseball & artist & baptist & communist & black lives \\
matter
\end{tabular}




\begin{tabular}{|l|l|l|l|l|}
\hline golf & designer & episcopal & liberal & feminist \\
\hline hockey & filmmaker & episcopalian & progressive & lgbta \\
\hline mma & musician & hindu & democrat & maga \\
\hline soccer & poet & jewish & conservative & mens rights \\
\hline softball & composer & lutheran & gop & nasty woman \\
\hline sports & comedian & methodist & republican & red pill \\
\hline tennis & comedienne & mormon & libertartian & the 99\% \\
\hline volleyball & performer & muslim & alt-right & woke \\
\hline & actor & presbyterian & & \\
\hline & actress & & & \\
\hline & playwright & & & \\
\hline
\end{tabular}

Table S1. Lists of keywords for each category.

A user counts for a category if they use any of the words within their bio. A user with the bio "GOP dad who likes baseball" counts once for Political Affiliation and once for Sports. We searched for whole word matches using regular expression pattern matching and ignoring case. From these counts, we normalize by the total count of observed users to compute a prevalence. Specifically, Prevalence = (Count of users with keyword) / (Total user count) *10,000. It is important to be clear that we are always counting users and never words. A bio that reads "Painter, musician and poet" counts as one user who matches the Arts category, even though there happen to be three pattern matches.

\section{Data}

From 2015 to the present, we have collected a random sample of millions of tweets, and created a digital snapshot of each tweeter's bio at the moment of observation. By comparing the usage of words in bios from year to year, we identify trends in how people describe themselves.

To obtain our sample of tweets, we used the Twitter Streaming API (Twitter, 2019). We filter this set to US users by examining the user-provided location. The location is entered by the user, and we filter to text that indicates a likely US location. We filter out locations that are likely not in the US (e.g. "London, UK") and select in text that indicates a US location (e.g. state names and formal abbreviations). 
From these many observations of tweets, we construct a much shorter list of unique users.

Specifically, we choose at random one and only one instance of a user's profile per year. Therefore, regardless of how many times a user was observed tweeting, their profile is present once and only once when computing prevalence. The number of unique users observed per year is contained in Table S2. This number is the denominator in every prevalence calculation.

\begin{tabular}{|r|r|}
\hline \multicolumn{1}{|l|}{ Year } & Unique User Count \\
\hline 2015 & $8,564,955$ \\
\hline 2016 & $10,227,688$ \\
\hline 2017 & $10,638,679$ \\
\hline 2018 & $10,310,854$ \\
\hline 2019 & $9,817,008$ \\
\hline 2020 & $10,181,678$ \\
\hline
\end{tabular}

Table S2. Unique user profiles observed per year.

\section{Limitations}

The reader must be aware that the dataset comprises a large but not complete sample of American users of Twitter. To be included, a user must indicate in their profile a likely US location. To be counted within a prevalence estimate in a category, they must use a word from the lists we constructed. Therefore, these results might not generalize to offline behavior or nations other than the US. Also, individuals' private, internal sense of self likely differs from their public expression of identity.

Nonetheless, we point out that this sample is vastly larger than samples used in most social science research and more inclusive than most behavioral research conducted on convenience samples of local college students. We analyze public expressions of identity, because we don't have access to the private, internal thoughts of anyone except ourselves.

One can imagine other ways to measure the "politicallness" or "religiousness" of bios that take more of the available language data into account. One could take a machine-learning approach to classify any bio on any dimension. However, the current approach has the benefits of clear operationalization and 
efficient computability. Replication of these results is straightforward. Any person and every algorithm can agree on whether or not a short text contains "atheist" or does not contain "atheist."

\section{Further Applications}

The current method could be applied to any word, phrase or regular expression. The current visualization uses US nationwide and annual data for ease of analysis and presentation, but daily temporal resolution and finer geographic resolution is possible with the same techniques. Further applications of this methodology will soon provide new insight into the temporal trends of shifting identity.

\section{References}

Abramowitz, Alan I., and Steven Webster. 2016. "The Rise of Negative Partisanship and the Nationalization of U.S. Elections in the 21st Century.” Electoral Studies 41:12-22.

Chua, Amy. 2018. Political Tribes: Group Instinct and the Fate of Nations. New York City: Penguin Press.

Eady, G., Hjorth, F., \& Dinesen, P. T. (2021). Do Violent Protests Affect Expressions of Party Identity?

Evidence from the Capitol Insurrection. https://osf.io/dvgj3/

Hetherington, Marc, and Jonathan Weiler. 2018. Prius or Pickup? How the Answers to Four Simple

Questions Explain America’s Great Divide. New York: Houghton Mifflin Harcourt.

Iyengar, Shanto, and Sean J. Westwood. 2015. "Fear and Loathing across Party Lines: New Evidence on Group Polarization.” American Journal of Political Science 59(3):690-707.

Jones, David R. 2001. "Party Polarization and Legislative Gridlock.” Political Research Quarterly 54(1):125-41.

Jones, J. J. (2021). A Dataset for the Study of Identity at Scale: Annual Prevalence of American Twitter Users with specified Token in their Profile Bio - 2015-2020. SocArXiv.

https://doi.org/10.31235/osf.io/cm5g7

Kuhn, Manford H., and Thomas S. McPartland. 1954. "An Empirical Investigation of Self-Attitudes." American Sociological Review 19(1):68-76.

Mason, Lilliana. 2018. Uncivil Agreement: How Politics Became Our Identity. Chicago: University of Chicago Press.

Pathak, A., Madani, N., \& Joseph, K. (2021). A Method to Analyze Multiple Social Identities in Twitter Bios. ArXiv:2107.14120 [Cs]. https://doi.org/10.1145/3479502

Pew Research Center. 2016. "Partisanship and Political Animosity in 2016.” Retrieved January 19, 2021 
(https://www.pewresearch.org/politics/2016/06/22/partisanship-and-political-animosity-in-2016/).

Rogers, N., \& Jones, J. J. (2021). "Using Twitter Bios to Measure Changes in Self-Identity: Are Americans Defining Themselves More Politically Over Time?" Journal of Social Computing, 2(1), 1-13. https://doi.org/10.23919/JSC.2021.0002

Sherif, Muzafer. 1958. "Superordinate Goals in the Reduction of Intergroup Conflict." American Journal of Sociology 63(4):349-56.

Sherif, Muzafer et al. 1961. Intergroup Conflict and Cooperation: The Robbers Cave Experiment. Norman, OK: University Book Exchange.

Sunstein, Cass R. 2002. “The Laws of Group Polarization.” Journal of Political Philosophy 10(2):17595.

Twitter. 2019. GET statuses/sample. Retrieved March 17, 2019, from https://developer.twitter.com/en/docs/tweets/sample-realtime/overview/GET_statuse_sample.html Zurcher, Louise. 1977. The Mutable Self: A Self Concept for Social Change. Beverly Hills, CA: Sage Publishing. 